\title{
Antenatal Depression and the Experiences of Australian Women in the Maternity System during the COVID-19 Pandemic
}

\author{
Lucy J. Frankham, Einar B. Thorsteinsson, Warren Bartik \\ Faculty of Medicine and Health, School of Psychology, University of New England, Armidale, Australia \\ Email: ethorste@une.edu.au
}

How to cite this paper: Frankham, L. J., Thorsteinsson, E. B., \& Bartik, W. (2021). Antenatal Depression and the Experiences of Australian Women in the Maternity System during the COVID-19 Pandemic. Open Journal of Depression, 10, 155-167. https://doi.org/10.4236/ojd.2021.104010

Received: August 2, 2021

Accepted: September 14, 2021

Published: September 17, 2021

Copyright $\odot 2021$ by author(s) and Scientific Research Publishing Inc. This work is licensed under the Creative Commons Attribution International License (CC BY 4.0).

http://creativecommons.org/licenses/by/4.0/

\begin{abstract}
The mitigation efforts of COVID-19 have led to significant changes to the delivery of routine healthcare globally. In Australia, the way maternal health services have been delivered since the beginning of the pandemic has also changed. Maternity care and support are known to influence maternal mental health. One hundred and eighty-eight English-speaking pregnant women residing in Australia were recruited using social media advertising between September and November 2020 as part of a larger study. Participants were aged between 19 and $42(M=31.05, S D=4.68)$. Compared with previous Australian prevalence rates of around 7\% for antenatal depression, rates in this study were $15.9 \%$ overall and $19 \%$ for those in Melbourne. Antenatal depression was positively associated with COVID-19 distress in relation to having a baby during a COVID-19 outbreak $r(186)=0.30, p<0.001$. It is suggested that increased vigilance with screening and assessment will be required to identify and support mothers who are not coping during the pandemic.
\end{abstract}

\section{Keywords}

Antenatal Depression, COVID-19, Pregnancy, Mental Health, Edinburgh

Postnatal Depression Scale

\section{Introduction}

The mitigation efforts of COVID-19 have led to significant changes to the delivery of routine healthcare globally. Many routine appointments have been cancelled, reduced or transitioned to telehealth; fewer visitors are permitted in hospitals and resources have been stretched (Koonin et al., 2020; Monaghesh \& Hajizadeh, 2020; Ralli et al., 2020; Sutherland et al., 2020). In Australia, the way 
maternity healthcare services have been delivered since the beginning of the pandemic has also changed (Cooper \& King, 2020). Women have reported fewer routine pregnancy checks, fewer face-to-face appointments and restrictions on birthing practices (e.g., use of water immersion). Women are being asked to birth with less support and attend many appointments alone (e.g., ultrasounds). Some of these decisions seem to be inconsistent with the evidence around COVID-19 mitigation, for example, the issue of water immersion for birthing (Australian College of Midwives, 2020). According to a report by the Australian College of Midwives (Cooper \& King, 2020), the psychosocial aspects of women's pregnancies have been different from what they anticipated and had previously imagined due to community restrictions. Some women have been unable to have the family and social support they anticipated due to restrictions on borders and travel; others have not been able to attend birthing classes, or the classes have been moved online. Many have been unable to have the desired birthing partner(s) they wanted with them or have experienced uncertainty about who will be able to attend.

There is an abundance of existing evidence confirming that the nature of maternity care available to women has an important influence on mental health outcomes for the mother and infant (e.g., Gidget Foundation, 2019; World Health Organisation, 2018, 2020). Healthcare guidelines and research frequently cite early identification and prevention as a way to improve mental health outcomes for mothers, their partners, and children (Gidget Foundation, 2019; Khanlari, Am et al., 2019a; Sandall et al., 2016). In Australia, mental health screening typically occurs during early pregnancy when preventative efforts are likely to be most efficacious and is recommended to be completed at least twice antenatally (Centre for Perinatal Excellence, 2021). The nature of maternity care provided has also been shown to significantly reduce rates of obstetric interventions, preterm birth and infant loss (Sandall et al., 2016). A report into the cost of perinatal depression and anxiety in Australia commissioned by the Gidget Foundation (2019) recommended services and treatment options should be supported by a high quality and comprehensive screening program and encourage access to informally and formally support networks for mothers and fathers alongside other community health interventions, describing it as invaluable. Due to the mitigation efforts of the pandemic, these optimal systems and processes of antenatal care in Australia are expected to have been compromised.

Psychosocial factors are known to increase the risk of postnatal depression (Gidget Foundation, 2019) and antenatal depression is a risk factor for the development of postnatal depression (Eastwood et al., 2017; Khanlari, Eastwood et al., 2019b; Milgrom et al., 2008). Research shows that postnatal depression can have long-lasting detrimental effects on families and children, as well as substantial economic costs to the community in the long term (Ayers et al., 2014; Bauer et al., 2014; Gidget Foundation, 2019; World Health Organisation, 2008, 2020). Maternal mental health difficulties are associated with poorer infant outcomes 
such as prematurity and low birth weight (Gidget Foundation, 2019) and can affect the physical, cognitive, social, behavioural and emotional development of children (World Health Organisation, 2008). Children of parents with postnatal depression are more likely to be diagnosed with Attention Deficit Hyperactivity Disorder, develop asthma or respiratory problems, have reduced immune system responses and neurodevelopmental issues (Gidget Foundation, 2019).

Since COVID-19, internationally, antenatal depression rates have been reported to have increased significantly. Using a cut-off score of $\geq 13$ on the Edinburgh Postnatal Depression Scale (Cox et al., 1987) other recent studies have found pandemic prevalence rates at $37 \%$ in a Canadian sample (Lebel et al., 2020 ) and $40.7 \%$ in a worldwide sample (Davenport et al., 2020), and using a cut off of $\geq 10$ (as recommended in Asian samples) prevalence rates were reported to be $34.2 \%$ in a Chinese sample (Wu et al., 2020). In Australia, pre-pandemic rates of antenatal depression are reported to be around 7\% (Buist et al., 2006; Eastwood et al., 2017; Khanlari, Eastwood et al., 2019b). There is no doubt that maternity care has been different for pregnant women in Australia and especially so in Melbourne where the second wave occurred. Melburnian mothers were subject to even stricter mitigation strategies with a lockdown enforced between July-October 2020. This paper reports prevalence rates of antenatal depression in Australian women during the second wave of the pandemic and explores the association between antenatal depression and distress in relation to COVID-19. Changes to maternity care are described qualitatively. The potential future impact due to the known effects of antenatal depression and poor maternity care is discussed.

\section{Method}

\subsection{Participants}

A convenience sample of one hundred and eighty-eight women was recruited using paid Facebook advertising between September and November 2020 as part of a larger study. Sample size was determined by the requirements of the larger study. Participants were required to be 18 years old or over, pregnant, English speaking and residing in Australia. Participants were invited to complete an online survey and were offered entry in a draw for a gift voucher as incentive to participate. Participants were aged between 19 and $42(M=31.05, S D=4.68)$. The project was approved by the Human Research Ethics Committee of the University of New England (HE20-159).

Participants were asked whether they lived in a rural, remote, or urban location. Longitude and latitude data collected by the survey tool Qualtrics ${ }^{\mathrm{TM}}$ was used determine participants located in Melbourne at the time of taking the survey. Participants were also asked about education, relationship status and ethnic background. In relation to their pregnancy, participants were also asked whether this was their first birth, where they planned to birth, and whether they were having a single or multiple birth. 


\subsection{Measures}

\subsubsection{Edinburgh Postnatal Depression Scale}

Antenatal depression was measured using the Edinburgh Postnatal Depression Scale (EDPS; Cox et al., 1987). The EPDS is a 10-item self-report questionnaire with higher scores on the scale indicating higher levels of distress. The EPDS has been found to be valid for screening perinatal distress (Baggaley et al., 2007; Bergink et al., 2011; Fernandes et al., 2011; Lee et al., 2001; Terry et al., 1996). The EPDS has established reliability and validity (Lee et al., 2001; Terry et al., 1996) including reliability in pregnancy ( $\alpha=0.82-0.84$; Bergink et al., 2011).

\subsubsection{COVID-19 Distress}

COVID-19 related distress was measured using a five-point Likert scale rated from 1 (no concern) to 5 (extremely concerned). Two questions were asked "In relation to having your baby, how concerned are you as a result of the COVID-19 outbreak?" and "Overall, how concerned are you as a result of the COVID-19 outbreak?" Participants were also asked the open-ended question: "Is your pregnancy care different due to the COVID-19 outbreak? If so, how?"

\subsubsection{Data Analysis}

The Statistical Package for the Social Sciences 21 (SPSS.21) program was used for quantitative analysis. Data were checked for accuracy, and invalid data were removed.

Qualitative themes were derived using the process of data familiarization, code generation, searching for themes and, reviewing and defining the themes, according Braun and Clarke's (2006) six step thematic analysis approach.

\section{Results}

\subsection{Participant Characteristics}

Most of the samples were white European nulliparous women with a university education planning a hospital birth in urban Australia. Five participants were not in a relationship and three reported being in a same sex relationship. Three women reported being pregnant with twins and sixteen were planning a birth either at home or in a private birthing centre. Thirteen women were having a planned caesarean. Characteristics of the sample are outlined in Table 1.

\subsection{Prevalence of Depression}

Using the cutoff of $\geq 13$ on the EPDS for probable depression (Cox et al., 1987; Cox et al., 1993) the prevalence rate for antenatal depression in this sample $(N=$ 188) was $15.9 \%$. Participants in Melbourne $(N=42)$ reported rates of antenatal depression at $19 \%$ and when removing Melbourne from the sample, the overall prevalence was reduced to $13.9 \%(N=124)$. Mean scores are reported in Table 2.

\subsection{COVID-19 Distress}

Mean scores for COVID-19 distress overall $(N=188)$ was $2.54(S D=0.98)$ indi- 
cating that on average mothers were "a little to moderately concerned" about the impact of COVID-19 on them overall. Participants in Melbourne $(N=42)$ reported a mean score of $2.84(S D=1.04)$ indicating they were more concerned compared

Table 1. Sample characteristics $(N=188)$.

\begin{tabular}{|c|c|c|}
\hline Characteristic & $n$ & $\%$ \\
\hline Nulliparous & 164 & 87.2 \\
\hline Multiparous & 24 & 12.8 \\
\hline \multicolumn{3}{|l|}{ Ethnic Background } \\
\hline Aboriginal or Torres Strait Islander & 2 & 1.1 \\
\hline White European & 130 & 69.1 \\
\hline Indian & 6 & 3.2 \\
\hline Asian & 24 & 12.8 \\
\hline Middle Eastern & 1 & 0.5 \\
\hline North American & 1 & 0.5 \\
\hline South American & 1 & 0.5 \\
\hline Mixed race & 11 & 5.6 \\
\hline Other & 12 & 6.4 \\
\hline \multicolumn{3}{|l|}{ Geographical location } \\
\hline Urban/City & 138 & 73.4 \\
\hline Rural & 43 & 22.9 \\
\hline Remote & 7 & 3.7 \\
\hline \multicolumn{3}{|l|}{ In a relationship } \\
\hline Yes & 183 & 97.3 \\
\hline No & 5 & 2.7 \\
\hline Same sex relationship & 3 & 1.6 \\
\hline \multicolumn{3}{|l|}{ Education } \\
\hline No formal qualifications & 2 & 1.1 \\
\hline Completed high school & 14 & 7.4 \\
\hline TAFE certificate/diploma & 51 & 27.1 \\
\hline University degree & 121 & 64.4 \\
\hline Single births & 185 & 98.4 \\
\hline Multiple birth-Twins & 3 & 1.6 \\
\hline Multiple birth-Triplets or more & 0 & 0 \\
\hline Birth education classes-yes & 115 & 61.2 \\
\hline Birth education classes-no & 73 & 38.8 \\
\hline Planned caesarean & 13 & 6.9 \\
\hline Birthing in hospital & 172 & 91.5 \\
\hline Birthing in private birth centre & 5 & 2.7 \\
\hline Birthing in home environment & 11 & 5.6 \\
\hline
\end{tabular}


Table 2. Means and standard deviations of distress measures.

\begin{tabular}{lccc}
\hline \multicolumn{1}{c}{ Measure } & $n$ & $M$ & $S D$ \\
\hline $\begin{array}{l}\text { Edinburgh Postnatal Depression Scale } \\
\quad \text { All locations }\end{array}$ & 188 & 7.50 & 5.47 \\
$\begin{array}{l}\text { Edinburgh Postnatal Depression Scale } \\
\quad \text { Melbourne }\end{array}$ & 42 & 8.40 & 5.24 \\
$\begin{array}{l}\text { Edinburgh Postnatal Depression Scale } \\
\quad \text { Outside Melbourne }\end{array}$ & 124 & 7.15 & 5.48 \\
$\begin{array}{l}\text { COVID Distress in relation to baby } \\
\quad \text { All locations }\end{array}$ & 188 & 2.32 & 0.98 \\
$\begin{array}{l}\text { COVID Distress in relation to baby } \\
\quad \text { Melbourne }\end{array}$ & 42 & 2.60 & 1.04 \\
$\begin{array}{l}\text { COVID Distress in relation to baby } \\
\text { Outside Melbourne }\end{array}$ & 124 & 2.22 & 0.96 \\
$\begin{array}{l}\text { COVID Distress Overall } \\
\text { All locations }\end{array}$ & & & \\
$\begin{array}{l}\text { COVID Distress Overall } \\
\text { Melbourne }\end{array}$ & 188 & 2.54 & 0.98 \\
$\begin{array}{l}\text { COVID Distress Overall } \\
\text { Outside Melbourne }\end{array}$ & 42 & 2.83 & 0.88 \\
\hline
\end{tabular}

Note: Of the 188 participants 22 had unknown location.

with the rest of Australia and when removing Melbourne from the sample $(N=$ $124)$, the overall mean was reduced to $2.45(S D=0.96)$.

Mean scores for mothers' COVID-19 distress in relation to having their baby $(N=188)$ was $2.32(S D=0.98)$ indicating that on average mothers were "a little to moderately concerned" about the impact of COVID-19 on their pregnancy and birth. Participants in Melbourne $(N=42)$ reported a mean score of 2.60 ( $S D$ $=0.88$ ) indicating they were more concerned compared with the rest of Australia and when removing Melbourne from the sample $(N=124)$, the overall mean was reduced to $2.22(S D=0.98)$ (Table 3$)$.

\subsection{Correlational Analyses}

Correlational analyses were used to examine the relationship between antenatal depression and the two measures of COVID-19 distress. Results indicated antenatal depression was positively associated with COVID-19 distress overall $r(186)$ $=0.17, p=0.017$ and in relation to having a baby during a COVID-19 outbreak $r(186)=0.30, p<0.001$. The greater the level of antenatal depression reported by mothers the more distressed they were about COVID-19 overall, and this relationship was stronger in relation to COVID-19 and their baby.

\subsection{Qualitative Analysis}

Responses to the question "Is your pregnancy care different due to the COVID-19 outbreak? If so, how?" generated four themes, in Table 4 and described below. 
Table 3. Prevalence above cut off for depression on the Edinburgh postnatal depression scale $(\geq 13)$ by location.

\begin{tabular}{ccc}
\hline Location & $\boldsymbol{n}$ & $\%$ \\
\hline All locations & 188 & 15.9 \\
Melbourne & 42 & 19.0 \\
Outside Melbourne & 124 & 13.9 \\
\hline
\end{tabular}

Table 4. Themes derived from the question "Is your pregnancy care different due to the COVID-19 outbreak? If so, how?” $(N=188)$

\begin{tabular}{lcc}
\hline \multicolumn{1}{c}{ Theme } & $\boldsymbol{n}$ & $\%$ \\
\hline $\begin{array}{l}\text { Changes to healthcare (e.g., face to face appointments/increased } \\
\text { telehealth/disconnect from health services) }\end{array}$ & 94 & 50.0 \\
$\begin{array}{l}\text { Reduced access to face to face birthing classes } \\
\begin{array}{l}\text { Less support (e.g., less hospital visitors and attendees at appointments) } \\
\text { No different or unsure if different }\end{array}\end{array}$ & 74 & 23.4 \\
\hline
\end{tabular}

Of the 188 responses only 42 mothers reported that there were no changes or that they were unsure of changes to their pregnancy care, indicating that more than three quarters of the mothers experienced some change to their pregnancy care.

\subsubsection{Changes to Healthcare}

Half of the mothers $(n=94)$ reported that their pregnancy healthcare was different. The most frequently reported change was the use of telehealth. Other changes included reduced routine checks, less birthing options, and more impersonal care. Examples of responses are shown below (spelling adjusted and abbreviations explained):

"I had to do all my appointments solo; a lot of appointments were forced online; my birth plan has been completely shut down and disregarded despite having no COVID-19 cases in our state. I was diagnosed with GD (gestational diabetes) and was given YouTube videos for education rather than an appointment with a dietician."

"More Telehealth, husband can't come to appointments to be informed, no glucose drink test, just a fasting sugar and Hbalc (average blood glucose level) test."

"Yes, many of the hospital check-up cancelled and turned to phone consultations."

"Hospital care feels very impersonal, staffs are stressed, decided to try for homebirth this week due to this."

"Yes, no classes, no tour of the hospital, barely any face to face appointments. Banning water birth has severely impacted my pregnancy."

"Everything is online-Telehealth consultations. I also am not able to attend birth education classes." 


\subsubsection{Less Support}

Reduced support was reported by 77 of the 188 mothers. The most common changes reported were having to attend appointments alone and only being allowed one birthing partner. Examples of responses are shown below (spelling adjusted and abbreviations explained):

"Some appointments have been telehealth. Some places won't allow a support person such as the imaging place in town meaning that if $i$ want my partner at an ultrasound we only have the option of going to the hospital. We have been advised only one support person is allowed when I am in labour."

"When I go into labour, I can only have 1 support person with me. My husband has a phobia of hospitals and all things medical so we originally had planned to have both him and mum with me. Now, since I can only have one person with me, I still don't know who I'm going to have with me."

"My husband was not able to attend ultrasounds which contributed to me declining ultrasounds."

"Yes, my husband is only allowed into scans for $5 \mathrm{~min}$ so it's not worth him having time off. Currently it is also 1 birth support person also."

"Husband is unable to attend midwife appointments and unsure if he will be able to visit for more than 2 hours after the baby arrives."

"Yes as I had planned to bring my parents from overseas but due to covid border restrictions they are not able to come and we had to be alone on ourselves."

\subsubsection{Reduced Access to Face to Face Birthing Classes}

Almost one quarter of the mothers reported having less or no access to face to face birthing classes. Examples of responses are shown below:

"Yes. My husband hasn't been able to be involved. I have had to pay for private birth classes as the hospital isn't running them. I am unable to plan to labour or birth in water. I have felt rushed and unsupported."

"Everything is online-Telehealth consultations. I also am not able to attend birth education classes."

"Yes. No face to face classes. Restricted antenatal care. Husband unable to attend appointments."

"Very. Missed all pre natal classes and many midwife face to face appointments."

"Yes, the parenting and birthing classes at hospital are cancelled, only my husband can come to the birth."

\subsubsection{No Different or Unsure if Different}

Of the 188 responses 42 mothers reported that there were no changes or that they were unsure of changes to their pregnancy care. While most women in this theme responded "no" to being asked if their pregnancy care was different due to the COVID-19 outbreak, some mothers stated that because it was their first baby, they were unsure if their care was different to usual. Examples of responses are shown below: 
"I'm not sure; I've never had a baby so I don't know what it is meant to be like."

"Not sure-entirety of pregnancy care has occurred during outbreak event and don't have much else to compare it to."

"I wouldn't know..."

\section{Discussion}

Prevalence rates of antenatal depression in this sample were found to be higher than Australian pre-pandemic prevalence rates. In the present study, the prevalence of antenatal depression was more than double the usual prevalence rate for Australia and in Melbourne the prevalence rate was almost three times higher than usual. Mean scores for COVID-19 related distress indicated that pregnant women were a little to moderately concern both overall and in relation to having their baby, with women in Melbourne reporting marginally higher mean scores. Overall, higher levels of antenatal depression were found to be significantly associated with higher levels of COVID-19 related distress and the strength of this relationship was higher in relation to distress about COVID-19 and the mother's baby.

More than half of the women reported changes to their pregnancy care, such as fewer appointments or the use of telehealth and nearly half reported less access to support, such as their chosen birthing partner(s) or having to attend appointments alone. Around a quarter reported changes to birthing classes with either no classes or online-only options. Less than one quarter reported their care to be no different indicating that most women experienced some differences in their overall pregnancy care. Overall, the responses women gave to the qualitative questions in relation to their concerns about COVID-19 painted a lonely isolating experience that lacked access to the quality of care and support previously afforded to Australian women. The volume of women in this sample who reported changes to their pregnancy care, along with distress about COVID-19 in relation to their baby, suggests that the reported changes to maternity care may have contributed to the increased prevalence rates of antenatal depression observed; however, it is beyond the scope of this study to determine this. Positively, despite the reported impact of the COVID-19 mitigation response on maternity care and increased prevalence rates of antenatal depression reported in this sample, Australia appears to be doing better than other countries with regard to antenatal depression prevalence rates during the pandemic (Davenport et al., 2020; Lebel et al., 2020; Wu et al., 2020).

\subsection{Limitations, Implications and Future Research}

The changing nature of COVID-19 and Australia's mitigation response means that the rates of antenatal depression observed in this sample are likely to shift and change along with the pandemic. This study had a small overall sample size that was drawn from a convenience sample of women recruited via Facebook 
who were mostly white European, university educated city dwellers, as such the results may not adequately represent the wider population. The scope of this study also did not allow exploration of causal explanations for increases in antenatal depression and therefore it is not clear exactly what aspects of COVID-19 were impacting women in this sample or why they were more depressed during this period. The mixed methodological approach of both qualitative and quantitative methods in this study does allow for greater richness in the interpretation of the data that was collected. Longitudinal studies that collect data at different stages throughout the pandemic will be needed to better understand the impact of Australia's COVID-19 mitigation efforts on the association between COVID-19 distress and antenatal depression.

High-quality and comprehensive maternity care involving both formal healthcare systems and informal supports are considered to be protective in combating maternal mental health problems (Fenwick et al., 2015; Gidget Foundation, 2019; Sandall et al., 2016; World Health Organisation, 2020). Based on the findings of this study, Australia's pandemic mitigation efforts have impacted the nature of routine maternity care and usual mental health protective practices. Women in this sample were distressed about COVID-19 and their baby and this was related to being more depressed during pregnancy. Further studies need to be conducted to determine what aspects of COVID-19 are influencing the increases in antenatal depression observed in this study.

\subsection{Conclusion}

Antenatal depression is an important risk factor for postnatal depression (Eastwood et al., 2017; Khanlari, Eastwood et al., 2019b; Milgrom et al., 2008) and leads to substantial economic costs to the community (Ayers et al., 2014; Bauer et al., 2014; Gidget Foundation, 2019; World Health Organisation, 2008, 2020). Based on the prevalence rates of antenatal depression observed in this study it will be important for further studies to determine if we have a concerning trend of increased maternal mental health problems ahead of us. It will be crucial for healthcare providers to maintain vigilance with assessment and screening of pregnant women and with postnatal follow-up. It suggested that current COVID-19 mitigation strategies should be reviewed to ensure that pregnant women are able to access as much "usual care" as possible with consideration to the importance of high-quality maternity care and support on long-term health outcomes. It is also suggested that existing funding of mental health services targeting women and families in the perinatal period should continue to be made available, and where possible targeted funding for services such as sustained home visiting programs should be increased for this group for an extended period to mitigate the potential social and economic burden on families and the community into the future.

\section{Conflicts of Interest}

The authors declare no conflicts of interest regarding the publication of this paper. 


\section{References}

Australian College of Midwives (2020, August 14). ACM's Updated Position on Use of Water in Labour.

https://www.midwives.org.au/news/acm-s-updated-position-use-water-labour

Ayers, S., Jessop, D., Pike, A., Parfitt, Y., \& Ford, E. (2014). The Role of Adult Attachment Style, Birth Intervention and Support in Posttraumatic Stress after Childbirth: A Prospective Study. Journal of Affective Disorders, 155, 295-298.

https://doi.org/10.1016/j.jad.2013.10.022

Baggaley, R., Ganaba, R., Filippi, V., Kere, M., Marshall, T., Sombie, I., Patel, V. et al. (2007). Detecting Depression after Pregnancy: The Validity of the K10 and K6 in Burkina Faso. Tropical Medicine and International Health, 12, 1225-1229. https://doi.org/10.1111/j.1365-3156.2007.01906.x

Bauer, A., Parsonage, M., Knapp, M., Lemmi, V., \& Adelaja, B. (2014). The Costs of Perinatal Mental Health Problems. Personal Social Services Research Unit. https://www.nwcscnsenate.nhs.uk/files/3914/7030/1256/Costs_of_perinatal_mh.pdf

Bergink, V., Kooistra, L., Lambregtse-van den Berg, M. P., Wijnen, H., Bunevicius, R., Van Baar, A., \& Pop, V. (2011). Validation of the Edinburgh Depression Scale during Pregnancy. Journal of Psychosomatic Research, 70, 385-389. https://doi.org/10.1016/j.jpsychores.2010.07.008

Braun, V., \& Clarke, V. (2006). Thematic Analysis Revised-Final. Qualitative Research in Psychology, 3, 77-101. https://doi.org/10.1191/1478088706qp063oa

Buist, A., Bilszta, J., Milgrom, J., Condon, J., Speelman, C., Hayes, B., Ellwood, D. et al. (2006). The Beyondblue National Postnatal Depression Program, Prevention and Early Intervention 2001-2005, Final Report. The National Depression Initiative.

Centre for Perinatal Excellence (2021). Using the EPDS as a Screening Tool. https://www.cope.org.au/health-professionals/health-professionals-3/calculating-scoreepds/

Cooper, M., \& King, R. (2020). Women's Experiences of Maternity Care at the Height of COVID-19. Australian College of Midwives.

Cox, J. L., Holden, J. M., \& Sagovsky, R. (1987). Detection of Postnatal Depression: Development of the 10-Item Edinburgh Postnatal Depression Scale. The British Journal of Psychiatry, 150, 782-786. https://doi.org/10.1192/bjp.150.6.782

Cox, J. L., Murray, D., \& Chapman, G. (1993). A Controlled Study of the Onset, Duration and Prevalence of Postnatal Depression. British Journal of Psychiatry, 163, 27-31. https://doi.org/10.1192/bjp.163.1.27

Davenport, M. H., Meyer, S., Meah, V. L., Strynadka, M. C., \& Khurana, R. (2020). Moms Are Not OK: COVID-19 and Maternal Mental Health. Frontiers in Global Women's Health, 1, 1-6. https://doi.org/10.3389/fgwh.2020.00001

Eastwood, J., Ogbo, F. A., Hendry, A., Noble, J., Page, A., \& Group, E. Y. R. (2017). The Impact of Antenatal Depression on Perinatal Outcomes in Australian Women. PLoS ONE, 12, e0169907. https://doi.org/10.1371/journal.pone.0169907

Fenwick, J., Toohill, J., Gamble, J., Creedy, D. K., Buist, A., Turkstra, E., Ryding, E. L. et al. (2015). Effects of a Midwife Psycho-Education Intervention to Reduce Childbirth fear on Women's Birth Outcomes and Postpartum Psychological Wellbeing. BMC Pregnancy and Childbirth, 15, Article No. 284. https://doi.org/10.1186/s12884-015-0721-y

Fernandes, M. C., Srinivasan, K., Stein, A. L., Menezes, G., Sumithra, R., \& Ramchandani, P. G. (2011). Assessing Prenatal Depression in the Rural Developing World: A Com- 
parison of Two Screening Measures. Archives of Women's Mental Health 14, 209-216. https://doi.org/10.1007/s00737-010-0190-2

Gidget Foundation (2019, November 7). The Cost of Perinatal Depression and Anxiety in Australia. Gidget Foundation.

https:/gidgetfoundation.org.au/wp-content/uploads/2019/11/Cost-of-PNDA-in-Austr alia_-Final-Report.pdf

Khanlari, S., Am, B. B., Ogbo, F. A., \& Eastwood, J. (2019a). Re-Examination of Perinatal Mental Health Policy Frameworks for Women Signalling Distress on the Edinburgh Postnatal Depression Scale (EPDS) Completed during Their Antenatal Booking-in Consultation: A Call for Population Health Intervention. BMC Pregnancy and Childbirth, 19, Article No. 211. https://doi.org/10.1186/s12884-019-2378-4

Khanlari, S., Eastwood, J., Barnett, B., Naz, S., \& Ogbo, F. A. (2019b). Psychosocial and Obstetric Determinants of Women Signalling Distress during Edinburgh Postnatal Depression Scale (EPDS) Screening in Sydney, Australia. BMC Pregnancy and Childbirth, 19, Article No. 407. https://doi.org/10.1186/s12884-019-2565-3

Koonin, L. M., Hoots, B., Tsang, C. A., Leroy, Z., Farris, K., Jolly, B., Tong, I. et al. (2020). Trends in the Use of Telehealth during the Emergence of the COVID-19 Pandemic-United States, January-March 2020. Morbidity and Mortality Weekly Report, 69, 1595-1599. https://doi.org/10.15585/mmwr.mm6943a3

Lebel, C., MacKinnon, A., Bagshawe, M., Tomfohr-Madsen, L., \& Giesbrecht, G. (2020). Elevated Depression and Anxiety among Pregnant Individuals during the COVID-19 Pandemic. Journal of Affective Disorders, 277, 5-13. https://doi.org/10.1016/j.jad.2020.07.126

Lee, D. T., Yip, A. S., Chiu, H. F., Leung, T. Y., \& Chung, T. K. (2001). Screening for Postnatal Depression: Are Specific Instruments Mandatory? Journal of Affective Disorders, 63, 233-238. https://doi.org/10.1016/S0165-0327(00)00193-2

Milgrom, J., Gemmill, A. W., Bilszta, J. L., Hayes, B., Barnett, B., Brooks, J., Buist, A. et al. (2008). Antenatal Risk Factors for Postnatal Depression: A Large Prospective Study. Journal of Affective Disorders, 108, 147-157. https://doi.org/10.1016/j.jad.2007.10.014

Monaghesh, E., \& Hajizadeh, A. (2020). The role of Telehealth during COVID-19 Outbreak: A Systematic Review Based on Current Evidence. BMC Public Health, 20, Article No. 1193. https://doi.org/10.1186/s12889-020-09301-4

Ralli, M., Minni, A., Candelori, F., Cialente, F., Greco, A., \& de Vincentiis, M. (2020). Effects of COVID-19 Pandemic on Otolaryngology Surgery in Italy: The Experience of Our University Hospital. Otolaryngology-Head and Neck Surgery, 163, 86-88. https://doi.org/10.1177/0194599820928970

Sandall, J., Soltani, H., Gates, S., Shennan, A., \& Devane, D. (2016). Midwife-Led Continuity Models versus Other Models of Care for Childbearing Women. Cochrane Database of Systematic Reviews, 4, Article ID: CD004667. https://doi.org/10.1002/14651858.CD004667.pub5

Sutherland, K., Chessman, J., Zhao, J., Sara, G., Shetty, A., Smith, S., Levesque, J.-F. et al. (2020). Impact of COVID-19 on Healthcare Activity in NSW, Australia. Public Health Research \& Practice, 30, Article ID: e3042030. https://doi.org/10.17061/phrp3042030

Terry, D. J., Mayocchi, L., \& Hynes, G. J. (1996). Depressive Symptomatology in New Mothers: A Stress and Coping Perspective. Journal of Abnormal Psychology, 105, 220-231. https://doi.org/10.1037/0021-843X.105.2.220

World Health Organisation (2008). Maternal Mental Health and Child Health Development in Low and Middle Income Families.

https://www.who.int/mental_health/prevention/suicide/mmh_jan08_meeting_report.pdf 
World Health Organisation (2018). Intrapartum Care for a Positive Birth Experience. World Health Organisation.

https://www.who.int/reproductivehealth/publications/intrapartum-care-guidelines/en/

World Health Organisation (2020). Maternal Mental Health.

https://www.who.int/mental_health/maternal-child/maternal_mental_health/en/

Wu, Y., Zhang, C., Liu, H., Duan, C., Li, C., Fan, J., Li, X. et al. (2020). Perinatal Depressive and Anxiety Symptoms of Pregnant Women during the Coronavirus Disease 2019 Outbreak in China. American Journal of Obstetrics and Gynecology, 223, 240-241.

https://doi.org/10.1016/j.ajog.2020.05.009 